\title{
Plant-extract-mediated biosynthesis of silver nanoparticles using Eleutherine americana bulb extract and its characterization
}

\author{
JULINDA ROMAULI MANULLANG ${ }^{1,3}$, RUDY AGUNG NUGROHO ${ }^{2,3}$, MIFTAKHUR ROHMAH ${ }^{1,3}$, \\ RUDIANTO $^{2}$, AMANDA QORYSUCHI ${ }^{2}$ \\ ${ }^{1}$ Department of Animal Science, Faculty of Agriculture, Universitas Mulawarman. Jl. Pasir Balengkong No.1, Kampus Gunung Kelua, Samarinda 75123, \\ East Kalimantan, Indonesia \\ ${ }^{2}$ Animal Physiology, Development, and Molecular Laboratory, Department of Biology, Faculty of Mathematics and Natural Sciences, Universitas \\ Mulawarman. J1. Barong Tongkok, Kampus Gunung Kelua, Samarinda 75123, East Kalimantan, Indonesia. Tel. +62-541-749140, \\ "email: rudyagung.nugroho@fmipa.unmul.ac.id,julindamanullang@yahoo.com \\ ${ }^{3}$ Research Center of Natural Products from Tropical Rainforest, Universitas Mulawarman. Jl. Kerayan, Kampus Gunung Kelua, Samarinda 75123, \\ East Kalimantan, Indonesia
}

Manuscript received: 20 November 2021. Revision accepted: 30 November 2021

\begin{abstract}
Manullang JR, Nugroho RA, Rohmah M, Rudianto, Qorysuchi A. 2021. Plant-extract-mediated biosynthesis of silver nanoparticles using Eleutherine americana bulb extract and its characterization. Nusantara Bioscience 13: 247-254. The plant-based biosynthesis of nanoparticles has gained increasing momentum due to being lower in cost and eco-friendly. This study aimed to biosynthesize nanoparticles from the ethanolic bulb extract of Eleutherine americana (Aubl.) Merr. Ex K.Heyne (Ea-AgNPs), then characterize EaAgNPs and determine their phytochemical content and antioxidant capacity. The Ea-AgNPs were synthesized using ethanolic extract of E. americana bulb along with various concentrations of $\mathrm{AgNO}_{3}(0.5-4 \mathrm{mM})$. The Ea-AgNPs were then characterized using UV-VIS spectroscopic, Scanning Electron Microscopy/ Energy Dispersive X-ray (SEM/EDX), Transmission Electron Microscopy (TEM), X-ray Powder Diffractometry (XRD), and Fourier-Transform Infrared Spectroscopy (FTIR) techniques. The results indicated that E. americana could be used to reduce $\mathrm{AgNO}_{3}$ to synthesize Ea-AgNPs, indicated by color change, and had optimum UV/VIS spectra at $400 \mathrm{~nm}$. The FTIR analysis found that Ea-AgNPs showed peaks at 2919, 2850, 1586, and $1031 \mathrm{~cm}^{1}$, containing several important bio compounds. Additionally, the XRD results found an amorphous Ea-AgNP peak with maximum intensity and proportion of silver occurring at 24 Theta. The particle size distribution curve of Ea-AgNPs showed a size of $10^{5} \mathrm{~nm}$. Furthermore, SEM/EDX analysis revealed an optical absorption characteristic peak at $3 \mathrm{keV}$. The EDX examination revealed three signals: a strong signal from the C atom $(70.99 \%)$, an $\mathrm{O}$ atom $(28.95 \%)$, and an Ag atom (0.06 \%). The TEM imaging also showed the characteristics of Ea-AgNPs. Some phytochemicals such as flavonoids, tannins, alkaloids, and saponins were found in Ea-AgNPs, with IC 50 values of $45.30 \mathrm{ppm}$.
\end{abstract}

Keywords: Antioxidant properties, characterization, Eleutherine americana, nanoparticle

\section{INTRODUCTION}

Medicinal plant extracts were used in a bottom-up single-pot synthesis strategy using a wet chemistry method to conduct the green synthesis of silver nanoparticles. This method is environmentally benign, and lownanotechnology has arisen from many disciplines of science and engineering, where novel concepts for modifying molecules and single atoms have been developed (Usman et al. 2020; Gottardo et al. 2021; Zhang et al. 2021). The application of nanomaterials is particularly popular within environmental and medical research in the fast-developing field of nanotechnology. Silver nanoparticles are distinctive among metallic nanoparticles (Crisan et al. 2021; Kaabipour and Hemmati 2021; Restrepo and Villa 2021); they are the most widely investigated by researchers worldwide due to their versatile applications, simplicity of synthesis, adaptability, shape, and large surface area.

Nanoparticles are also broadly applied in biomedicine, agriculture, and poultry feed fields. In biomedicine, nanoparticle plant-based extract demonstrated significant antibacterial activity against various pathogenic microorganisms and cytotoxic action in the A549 and HepG2 cell lines (Acay 2021). Meanwhile, several studies have investigated the effects of nanoparticles on seed germination, growth stimulation, and metabolic rate changes (Goswami and Mathur 2019). However, nanoparticles also have negative consequences, such as suppressing plant development, inhibiting chlorophyll synthesis, and lowering photosynthetic efficiency (Goswami and Mathur 2019). In poultry, because of their huge surface area to volume ratio and rapid absorption in the body, nanoparticles may be introduced to animal feed, providing an ideal platform for incorporating a diverse range of substances such as vaccinations and vitamin supplements. Nanoparticles can also facilitate the direct delivery of chemicals to specific organs or systems while avoiding the rapid degradation caused by antibiotics, resulting in various health advantages (Singh and Lillard 2009).

Nanoparticles are often made using various chemical and physical processes that are costly and potentially harmful to the environment (Guo, 2012; Uzair et al. 2020). As a result, green synthesis approaches are gradually being linked with current scientific and industrial advancements 
in the global endeavor to decrease hazardous waste production. This study costs and produces stable, welldispersed silver nanoparticles with little aggregation and good size control (Iravani and Varma 2020; Velsankar et al. 2020).

In the present study, an extract of Eleutherine americana (Aubl.) Merr. Ex K. Heyne was employed as a reducing and stabilizing agent. Eleutherine americana (Dayak onion) is traditionally used as an ethnomedicine (Kamarudin et al. 2021); the bulb of this species is an essential traditional medicine used by Dayak tribes to treat heart illness, as an anti-inflammatory, to improve breastmilk production, diabetes, breast cancer, stroke, hypertension, sexual problems, and as a bacterial infection therapy (Ifesan et al. 2009; Song et al. 2009; Saragih et al. 2014; Nuryanto and Paramita 2018). The bulbs contain naphthalene, naphthoquinone, and anthraquinone (Mahabusarakam et al. 2010; Insanu et al. 2014) and phenolic compounds, which have powerful antioxidant effects and may be involved in the treatment of some diseases (Kuntorini et al. 2016). Furthermore, an oligosaccharide extract from $E$. americana has been utilized as a prebiotic to promote the development of gut flora (Phoem et al. 2019).

Plant extract as a reducing and stabilizing agent in the green production of silver nanoparticles is a new approach of interest to numerous scientists. Fatimah and Aftrid (2019) worked on the biosynthesis of AgNPs using red spinach (Amaranthus tricolor) leaf extract and investigated its antibacterial activity, while Kedi et al. (2018) synthesized AgNPs from Selaginella myosurus. Another study performed by Jalilian et al. (2020) focused on the green synthesis of AgNPs using Allium ampeloprasum aqueous extract and investigated their characterization, antioxidant activity, and antibacterial and cytotoxicity effects. Finally, Vijayakumar et al. (2019) used garlic clove extract to produce AgNPs, and further assessed their antibacterial, antibiofilm, anthelminthic, anti-inflammatory, anticancer, and ecotoxicity characteristics. Other research on the biosynthesis of AgNPs using various plant extracts are as follows: Oscillatoria sp. extracts (Adebayo-Tayo et al. 2019), cauliflower extract (Oda et al. 2019), and the bulb of Myrmecodia sp. (Nugroho et al. 2021).

Despite the previous research in this field, the experimental biosynthesis and characterization of silver nanoparticles mediated using the E. americana bulb as a reducing and stabilizing agent are not fully understood. Thus, the present work aimed to biosynthesize silver nanoparticles from $E$. americana bulb-mediated extract (Ea-AgNPs), characterize the resulting Ea-AgNPs, evaluate their phytochemical content, and determine the DPPH radical scavenging assay for the Ea-AgNPs.

\section{MATERIALS AND METHODS}

\section{Chemicals and extract preparation}

All chemicals, such as $\mathrm{AgNO}_{3}$, were obtained from Sigma Aldrich, MO, USA. The E. americana bulbs were purchased from a local herbal market in Samarinda, East Kalimantan, Indonesia. The identity of the E. americana was confirmed by a taxonomist working at Universitas Mulawarman. Next, to obtain bulb extract of E. americana, the bulb was cleaned using distilled water, thinly chopped into small pieces, and soaked using ethanol (10 g per 100 $\mathrm{mL})$. After 48 hours, the mixture was filtered and vacuum dried using a rotary evaporator. Finally, a dark brownish color E. americana bulb ethanolic extract was obtained and stored at $4^{\circ} \mathrm{C}$ until further use.

\section{Ea-AgNPs synthesis}

Furthermore, to synthesize the Ea-AgNPs, $10 \mathrm{~mL}$ of $\mathrm{AgNO}_{3}$ solution at various concentrations $(0.5,1,2,3$, and $4 \mathrm{mM}$ ) was prepared and added to $1 \mathrm{~mL}$ of $E$. americana bulb ethanolic extract. The synthesis was performed for 24 $\mathrm{h}$ at room temperature in a dark bottle to minimize the photo-activation of $\mathrm{AgNO}_{3}$. The color shift of the solution from colorless to brown confirmed the reduction of $\mathrm{Ag}$ to Ag0; UV-Visible spectroscopy was also used to validate its formation.

\section{Ea-AgNPs characterization}

The Ea-AgNPs, which were obtained from maximum absorbance $(1 \mathrm{~mL}$ extract of E. americana and $10 \mathrm{~mL}$ of $\mathrm{AgNO}_{3} 4 \mathrm{mM}$ ) freeze-dried and characterized using UVVisible Spectroscopy (UV-VIS; Spectrophotometer SPUN52N, Beijing China), Scanning Electron Microscopy (SEM; JEOL, Tokyo, Japan), Transmission Electron Microscopy (TEM; JEM 2100F JEOL, Tokyo, Japan), Fourier-Transform Infrared Spectroscopy (FTIR; 1000 FTIR spectrometer, Perkin Elmer), and X-ray Fluorescence (XRF; EDAX Bruker, Bavaria, Germany).

\section{Phytochemicals analysis of Ea-AgNPs}

The presence of phenols, saponins, triterpenes, flavonoids, alkaloids, and steroids in the Ea-AgNPs was determined using phytochemical screening. The screening process was carried out according to the technique described previously by Dada et al. (2018) and Senguttuvan et al. (2014).

\section{Antioxidant activities}

The antioxidant activity of Ea-AgNPs was determined using the DPPH radical scavenging test. The Ea-AgNPs' capacity to scavenge free radicals has previously been evaluated using the stable radical DPPH approach (Lateef et al. 2015). One milliliter of Ea-AgNPs in methanol at different concentrations $(0.08,0.1,0.12,0.14$, and 0.16 $\mathrm{mg} / \mathrm{mL}$ ) was added to four milliliters of a $0.1 \mathrm{mmol} \mathrm{L}^{-1}$ methanolic solution of DPPH. A blank was also prepared by diluting $1 \mathrm{~mL}$ methanol in $4 \mathrm{~mL} \mathrm{DPPH}$. The samples were incubated for 30 minutes in the dark at room temperature. The absorbance $(517 \mathrm{~nm})$ was measured against the prepared blank. The percent inhibition of free radicals by DPPH was estimated using the following formula: 
Inhibition $\%=\frac{\text { (Acontrol-A sample) }}{\text { Acontrol }} \times 100$

Where $\mathrm{A}_{\text {control }}$ is the absorbance of the control reaction (containing all reagents except the test compound) and $\mathrm{A}_{\text {sample }}$ is the absorbance of the test compound.

\section{RESULTS AND DISCUSSION}

\section{Biosynthesis of Ea-AgNPs}

The addition of E. americana bulb extract to the aqueous $\mathrm{AgNO}_{3}$ solution resulted in a change in the color of the solution from dark yellowish to reddish-brown (Figure 1) during the reaction, owing to the excitation of surface plasmon vibrations in the silver nanoparticles (Ider et al. 2017). Furthermore, silver nanoparticles were produced at various $\mathrm{AgNO}_{3}$ concentrations with ethanolic extract of $E$. americana bulb, as evidenced by the plasmon resonance band found at $410 \mathrm{~nm}$ within the UV spectra (corresponding to Ea-AgNPs); $\mathrm{AgNO}_{3}$ had an absorbance peak at $300 \mathrm{~nm}$, and the ethanolic extract of E. americana bulb had a peak at between 500-600 nm. These findings are comparable with Pandian et al. (2015), stating that EaAgNPs shows a characteristic peak absorbance wavelength between 400-500 nm (Figure 2). Previous research has also noted that silver nanoparticles absorb light between 400 and $500 \mathrm{~nm}$ due to their surface plasmon resonance (Prathna et al. 2011). Therefore, the optimum peak of 410 $\mathrm{nm}$ for Ea-AgNPs derived from $4 \mathrm{mM} \mathrm{AgNO}_{3}$ added with E. americana bulb extract indicates the biogenesis of $\mathrm{Ag}$ nanoparticles (Figure 3). The current work also shows that Ag nanoparticles are extremely stable in solution, even six days after their synthesis, which significantly confirms the suitability of E. americana ethanolic bulb extract for the production of AgNPs.
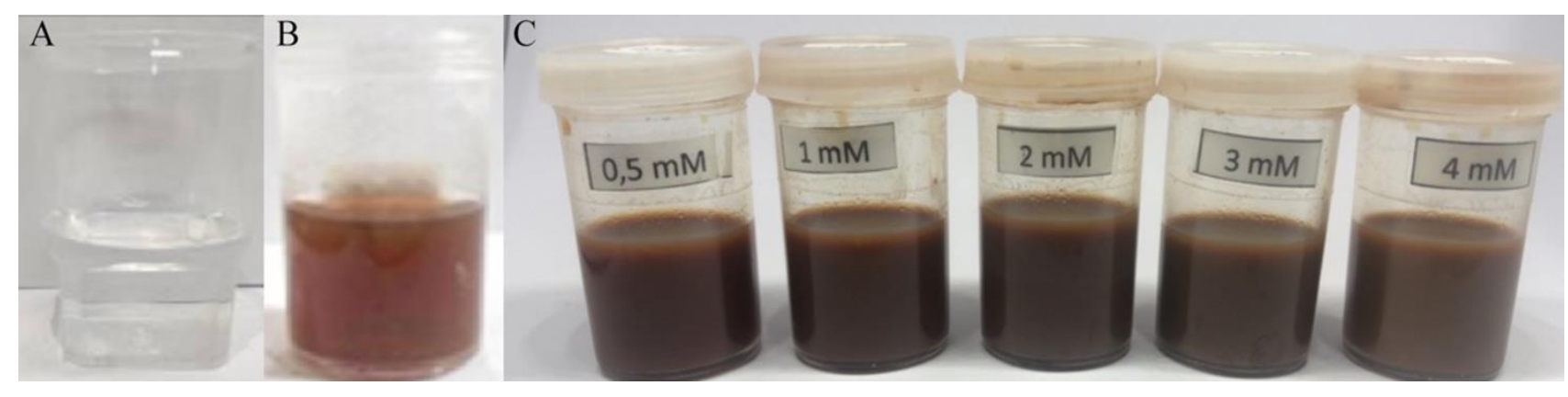

Figure 1. A. A solution of $\mathrm{AgNO}_{3}$, B. Dark yellowish ethanolic extract of Eleutherine americana bulb, C. Reddish-brown solution of Ea-AgNPs with different mixture concentrations of $\mathrm{AgNO}_{3}(0.5-4 \mathrm{mM})$

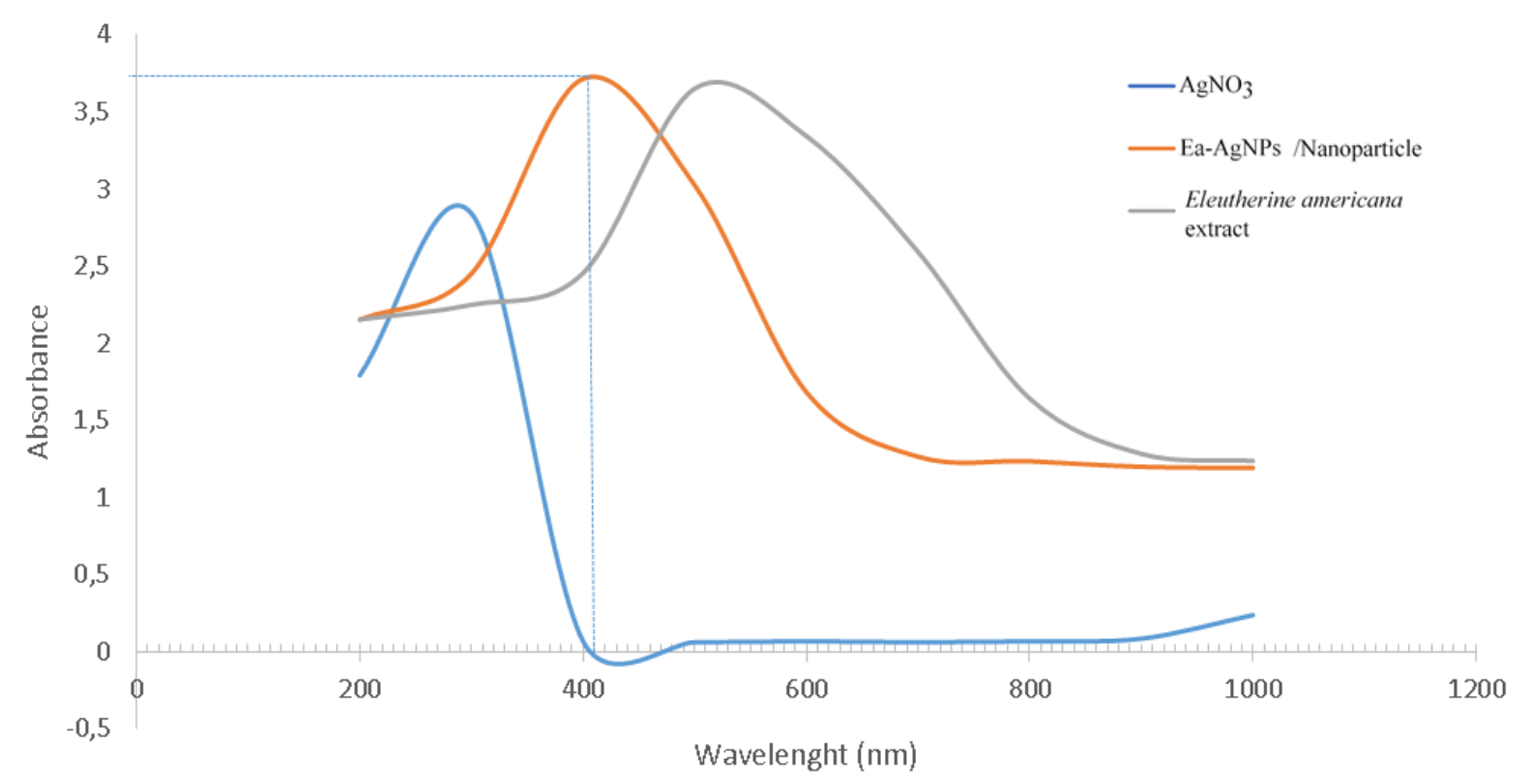

Figure 2. UV-VIS spectra of green synthesis of silver nanoparticles (Ea-AgNPs) using ethanolic extract of Eleutherine americana bulb and $4 \mathrm{mM}$ of $\mathrm{AgNO}_{3}$ 


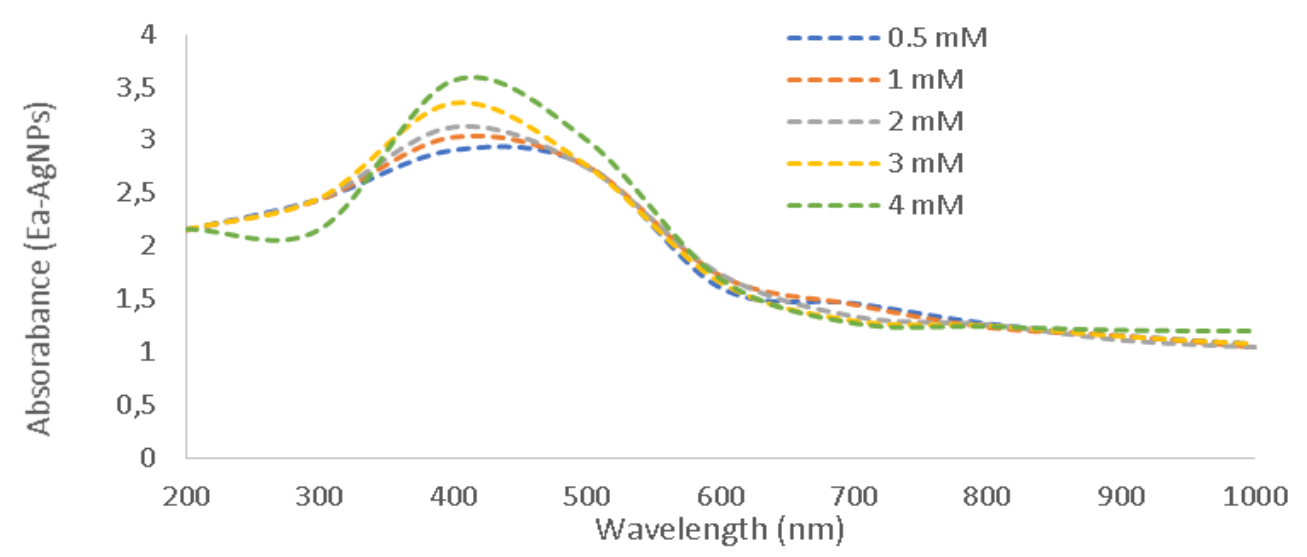

Figure 3. UV/VIS spectra characterization, showing the production of Ea-AgNPs at various concentrations of $\mathrm{AgNO}_{3}$

\section{Ea-AgNPs characterization}

The FTIR analysis was used to determine the various functions of reducing metals to metal nanoparticles. Figure 4 shows the infrared spectrum of biogenic Ea-AgNPs, with four significant bands detected at wavenumbers 2919, 2850, 1586, and $1031 \mathrm{~cm}^{1}$. At 2919 and $2850 \mathrm{~cm}^{1}$, a wide peak corresponds to the asymmetric and symmetric stretching $v(\mathrm{C}-\mathrm{H})$ vibrations of the methylene group of aliphatic compounds, respectively. The absorption peak at $1586 \mathrm{~cm}^{1}$ likely corresponds to the carboxyl group's $v(-$ COO) stretching frequency. In contrast, the band at 1031 $\mathrm{cm}^{1}$ is attributed to the $\mathrm{C}-\mathrm{O}$ stretching vibration of the carbohydrate residues.

In addition, the X-ray Powder Diffractometry (XRD) pattern indicated that the Ea-AgNPs were naturally amorphous (Figure 5), which is consistent with previously published results (Umadevi et al. 2012). Based on the particle size analysis (Figure 6), the resulting Ea-AgNPs had a size of more than $1 \mathrm{um}$, which might be caused by agglomeration, and the distribution of particles size of EaAgNPs was found to be $24.59 \%$ of $6667.10 \mathrm{~nm}$ and 75.41 $\%$ of $7532.65 \mathrm{~nm}$.

\section{SEM and EDS Analysis of Ea-AgNPs}

The presence of Ea-AgNPs was examined using Energy-Dispersive Spectroscopy (EDS) and SEM (Figure 7). The elemental composition of the Ea-AgNPs' nanocomposite film was determined using Energy Dispersive X-ray analysis (EDX), with the EDX spectrum of the Ea-AgNPs nanocomposite shown in Figure 8. The SEM image of the Ea-AgNPs (Figure 7) demonstrates that almost all nanoparticles are widely dispersed throughout the plant extract.

The SEM/EDX was used to determine the nanoparticles' surface morphology and elemental composition (Anake et al. 2016). Figure 7 depicts the morphology of the Ea-AgNPs produced as amorphous aggregates. The EDX analysis was used to determine the elemental components and relative abundance of biosynthesized Ea-AgNPs, as shown in Figure 8 . The purity and entire chemical composition of the Ea-AgNPs are shown by the EDX spectrum (Figure 8). The percentage content of Ag metal present in association with other chemical elements was discovered to be significant. The EDX spectrum revealed an optical absorption characteristic peak corresponding to Ag at $3 \mathrm{keV}$. Overall, the EDX examination revealed three signals: a strong signal from $\mathrm{C}$ atoms $(70.99 \%)$, in addition to signals from $\mathrm{O}$ atoms $(28.95 \%)$ and $\mathrm{Ag}$ atoms $(0.06 \%)$. Other elements or impurities did not exhibit obvious peaks. For example, metal silver nanoparticles have a typical optical absorption peak at about $3.7 \mathrm{keV}$; however, the additional peaks for $\mathrm{C}$ and $\mathrm{O}$ indicate that the nanoparticles are mixed into precipitates in the plant extract.

\section{TEM characterization}

Following confirmation of the formation of Ea-AgNPs through color change observation and UV/VIS absorption spectra, the size, shape, and morphology of Ea-AgNPs were investigated using TEM examination. The TEM images show that the powder particles were amorphous in form and agglomerated (Figure 9); the Ea-AgNPs were successfully formed, with an average particle size of $\sim 1 \mu \mathrm{m}$.

\section{The phytochemical contents and DPPH assay}

The phytochemical contents in the Ea-AgNPs are summarized in Table 1. The presence of alkaloids, flavonoids, phenolics, tannins, and coumarin was observed in the Ea-AgNPs.

The results indicate that the EA-AgNPs contain several important phytochemicals, including alkaloids, flavonoids, phenolics, tannins, and coumarin (Table 1). These results are similar to findings from previous studies, which revealed that silver nanoparticles from Sargassum tenerrimum contain several phytochemicals (Kumar et al. 2012). Furthermore, some phytochemicals, such as flavonoids, tannins, alkaloids, and saponins, which are found in Ea-AgNPs, may exhibit antibacterial properties (Rai et al. 2020; Nahar et al. 2021). Meanwhile, DPPH assays were used to assess the antioxidant activity of EaAgNPs; the results indicate that the Ea-AgNPs have a higher free radical inhibition percentage, with $\mathrm{IC}_{50}$ values of $45.30 \mathrm{ppm}$ (Table 2). 


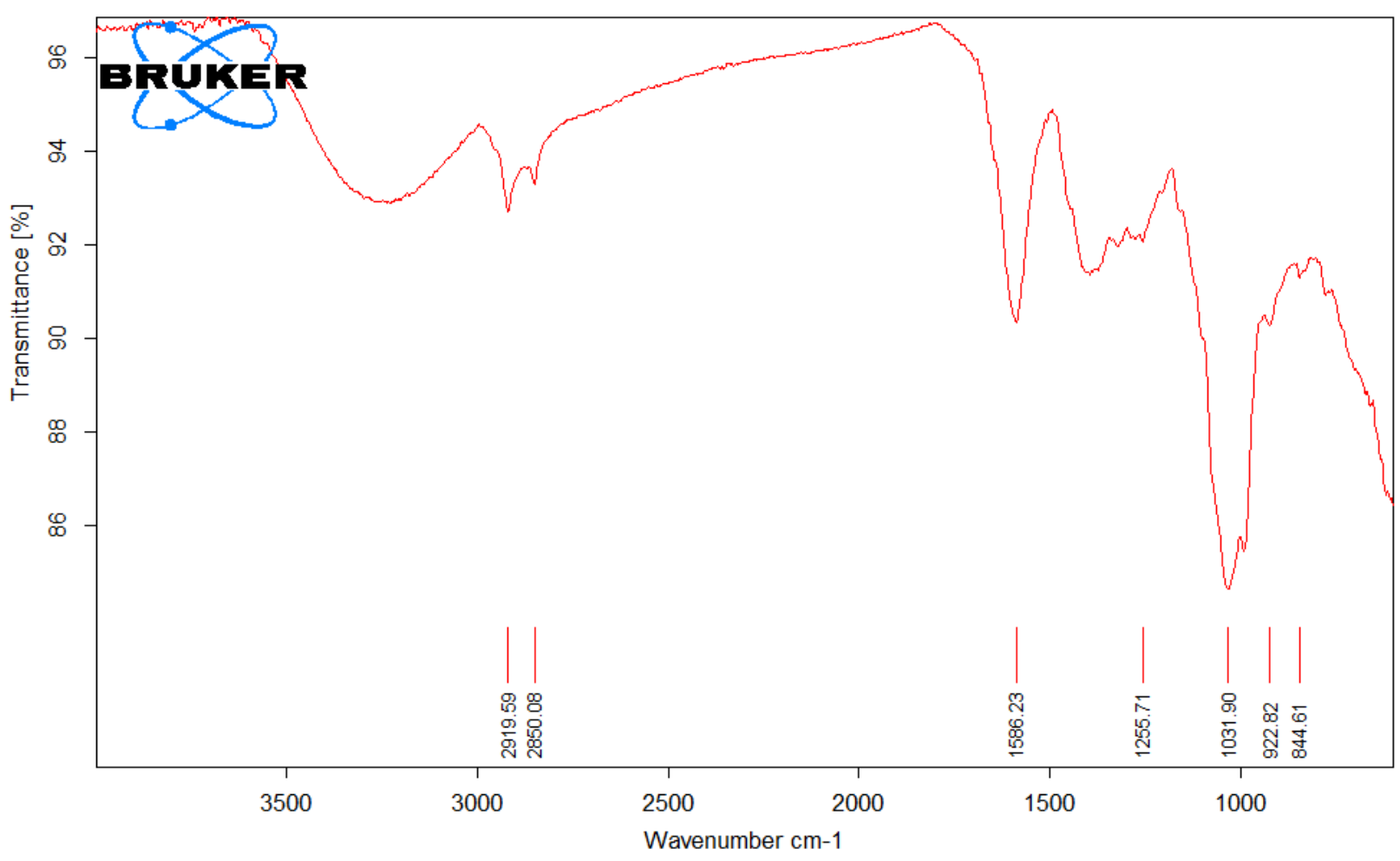

Figure 4. Fourier-transform infrared spectroscopy (FTIR) spectra of green synthesized silver nanoparticles (Ea-AgNPs) using ethanolic extract of Eleutherine americana and $4 \mathrm{mM} \mathrm{AgNO}_{3}$; peaks at 2919,2850,1586, and $1031 \mathrm{~cm}^{1}$ were due to C-H methylene group of aliphatic compounds, (-COO) stretching frequency of carboxyl group, and $\mathrm{C}-\mathrm{O}$ stretching vibration of the carbohydrate residues, respectively

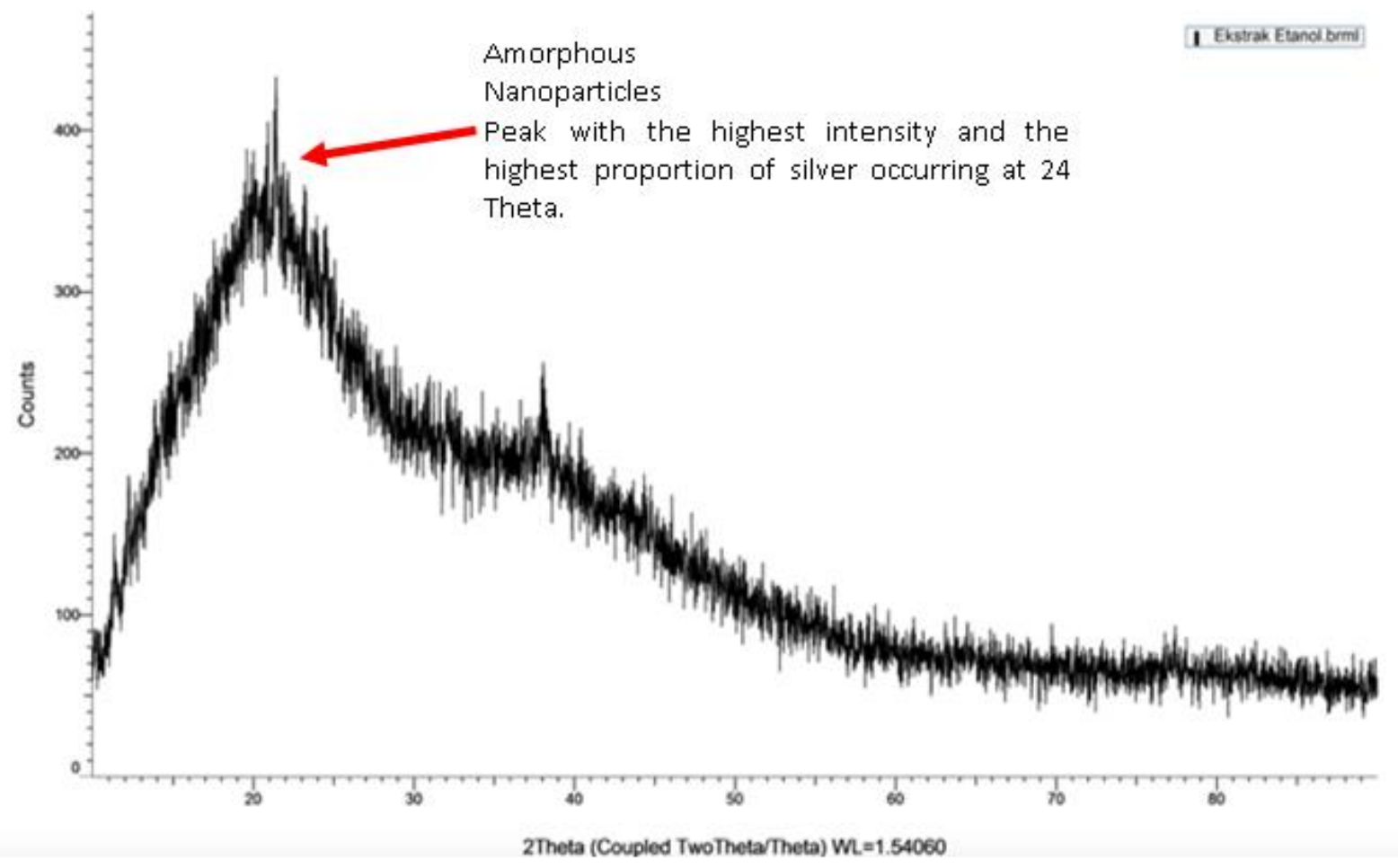

Figure 5. The X-ray Powder Diffractometry (XRD) pattern of the green synthesized silver nanoparticles mediated by Eleutherine americana (AgNPs); there was no characteristic peak which revealed the amorphous structure of nanoparticles 


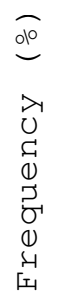

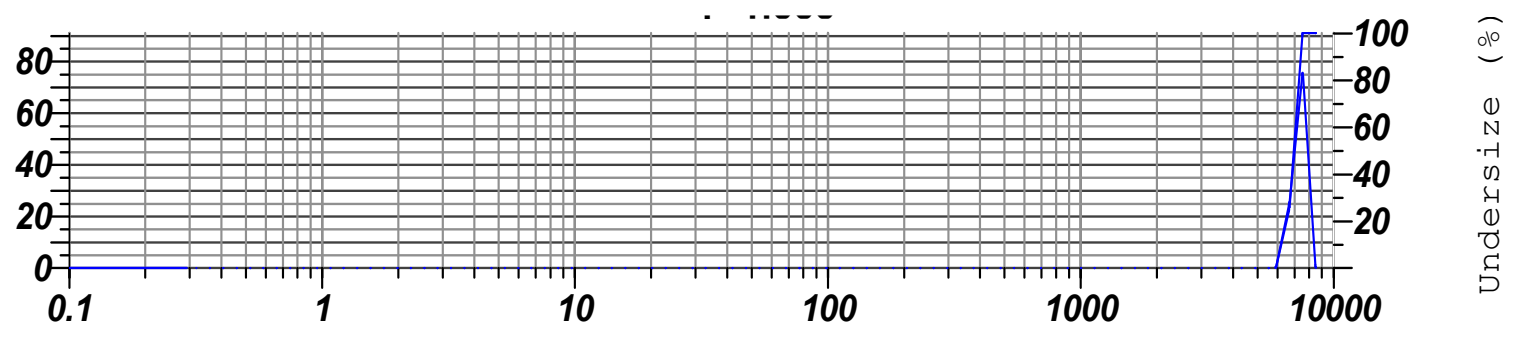

Diameter $(\mathrm{nm})$

Figure 6. The particle size distribution curve of silver nanoparticles (Ea-AgNPs) complexes was obtained by particle size analyzer; the Ea-AgNPs were obtained from the combination of ethanolic extract of Eleutherine americana and $4 \mathrm{mM} \mathrm{AgNO}_{3}$
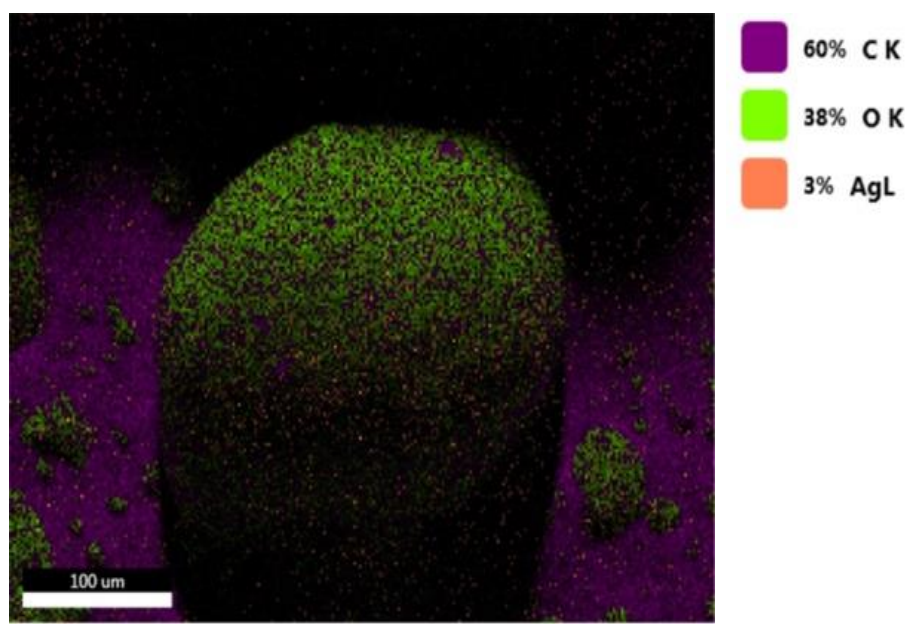

Figure 7. Scanning Electron Microscopy (SEM) images of the reduction of $\mathrm{Ag}^{+}$to Silver nanoparticles

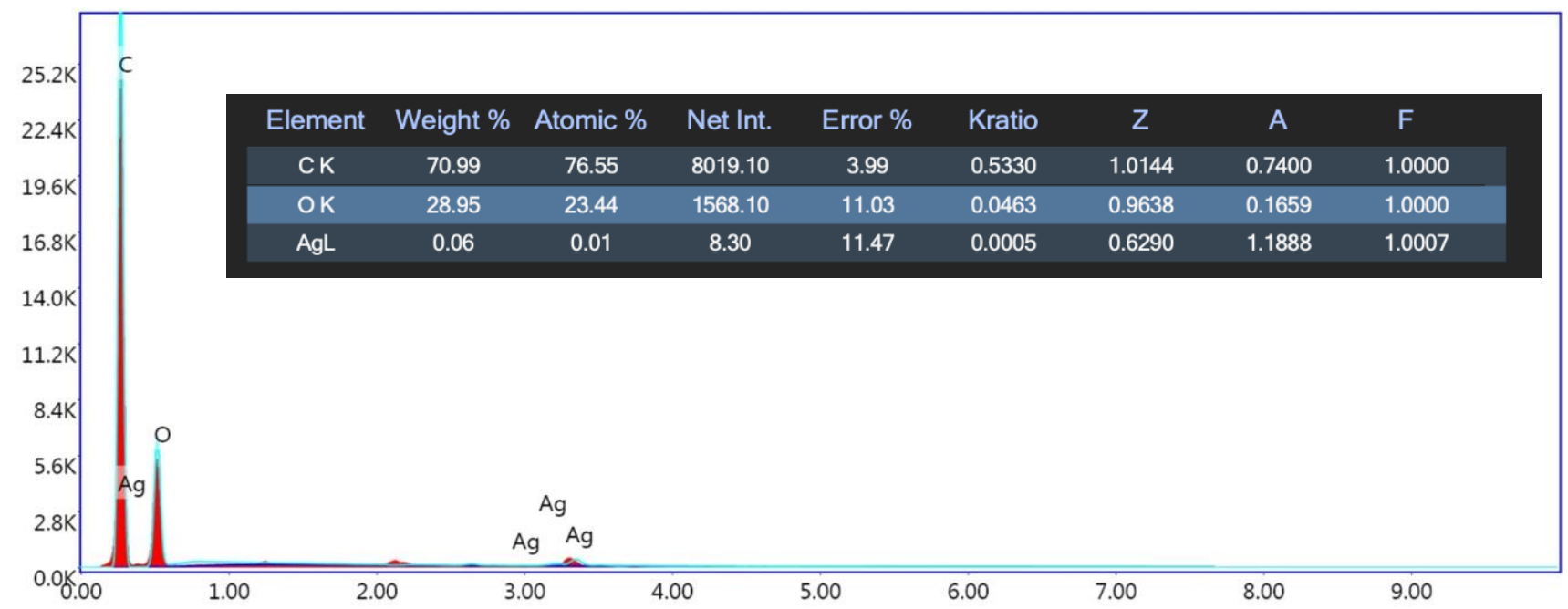

Figure 8. The Energy Dispersive X-ray (EDX) spectrum analysis of Eleutherine americana silver nanoparticle (Ea-AgNPs) 


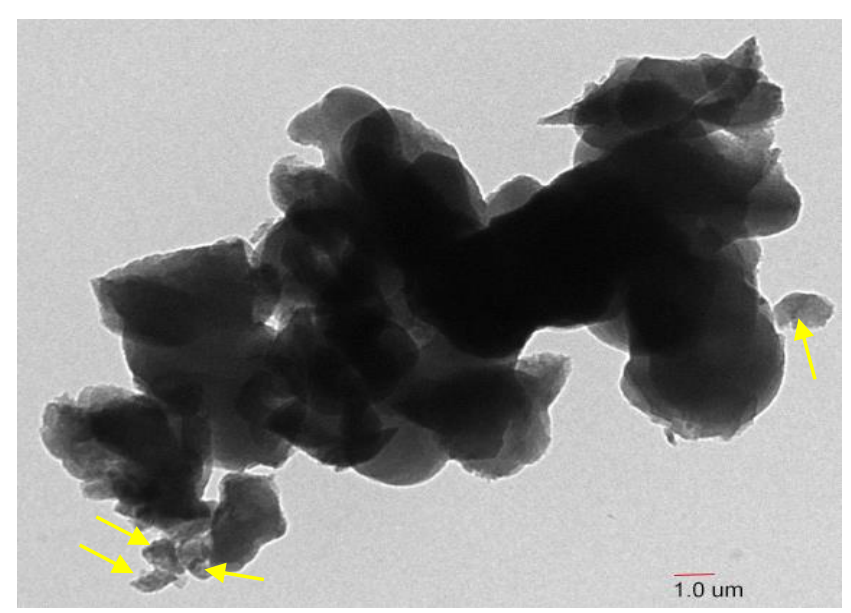

Figure 9. Transmission Electron Microscopy (TEM) micrographs of the green synthesized silver nanoparticles (AgNPs), mediated by Eleutherine americana bulb aqueous extract

Table 1. Ea-AgNPs phytochemicals content

\begin{tabular}{lc}
\hline Phytochemicals & Indicator \\
\hline Alkaloid & + \\
Flavonoid & + \\
Phenolic & + \\
Saponin & - \\
Triterpenoid & - \\
Steroid & - \\
Tannin & + \\
Glycoside & - \\
Coumarin & + \\
Carotenoid & - \\
\hline
\end{tabular}

Note: (+) Present, (-) Absent

Table 2. Antioxidant activity

\begin{tabular}{lc}
\hline Antioxidant (\%) & Sample concentration (ppm) \\
\hline 49.67685398 & 80 \\
57.31063763 & 100 \\
58.4287385 & 120 \\
59.37676585 & 140 \\
64.46053971 & 160 \\
$\mathrm{IC}_{50}$ & $45.30 \mathrm{ppm}$ \\
\hline
\end{tabular}

Plants are well-known to contain many phenolic and flavonoid compounds, which may have superior antioxidative properties and are regarded as potent free radical scavengers (Mustafa et al. 2010). The present $\mathrm{IC}_{50}$ value showed that the Ea-AgNPs have significant antioxidant action. Large molecular weight values and the closeness of multiple aromatic rings and hydroxyl groups are crucial for bioactive compounds' free radical scavenging action (Hagerman et al. 1998). Further, Panneerselvam et al. (2011) demonstrated the in vitro antioxidant capacity of synthesized silver nanoparticles mediated by Andrographis paniculata (Acanthaceae) using a DPPH radical scavenging test, which corroborates the findings of our study.
In conclusion, this study demonstrates the successful synthesis of Ea-AgNPs using ethanolic extract of $E$. americana bulb. An optimum UV/VIS spectrum absorption peak at $400 \mathrm{~nm}$ was found, corresponding to the resulting Ea-AgNPs. The FTIR analysis revealed several important bio compounds, and XRD characterization found an amorphous Ea-AgNP peak at 24 Theta. Meanwhile, the particle size distribution curve of Ea-AgNPs showed a size of $10^{5} \mathrm{~nm}$, with an optical absorption characteristic peak at $3 \mathrm{keV}$ observed via SEM/EDX analysis. The EDX examination revealed three signals: a strong signal from $\mathrm{C}$ atoms $(70.99 \%)$ and signals from $\mathrm{O}$ atoms $(28.95 \%)$ and $\mathrm{Ag}$ atoms $(0.06 \%)$. The TEM imaging also showed the characteristics of Ea-AgNPs. Phytochemical screening tests identified the presence of some phytocompounds such as flavonoids, tannins, alkaloids, and saponins in the EaAgNPs and showed $\mathrm{IC}_{50}$ values of $45.30 \mathrm{ppm}$.

\section{ACKNOWLEDGEMENTS}

The authors thank the Department of Veterinary and the Department of Biology, Universitas Mulawarman, Indonesia, for all their kind support. The authors are also grateful thankful the ministry of research and technology, research and innovation, Indonesia, for the financial funding (2021), through Hibah PTUPT contract number: (No. 297/E4.1/AK.04.PT/2021).

\section{REFERENCES}

Acay H. 2021. Utilization of Morchella esculenta-mediated green synthesis golden nanoparticles in biomedicine applications. Prep Biochem Biotechnol 51 (2): 127-136. DOI: 10.1080/10826068.2020.1799390.

Adebayo-Tayo B, Salaam A, Ajibade A. 2019. Green synthesis of silver nanoparticle using Oscillatoria sp. extract, its antibacterial, antibiofilm potential and cytotoxicity activity. Heliyon 5 (10): 1-8. DOI: 10.1016/j.heliyon.2019.e02502.

Anake WU, Ana GR, Benson NU. 2016. Study of surface morphology, elemental composition and sources of airborne fine particulate matter in Agbara Industrial Estate, Nigeria. Intl J Appl Environ Sci 11 (4): 881-890.

Crisan CM, Mocan T, Manolea M, Lasca LI, Tăbăran FA, Mocan L. 2021. Review on silver nanoparticles as a novel class of antibacterial solutions. Appl Sci 11 (3): 1-18. DOI: 10.3390/app11031120.

Dada AO, Inyinbor AA, Idu IE, Bello OM, Oluyori AP, Adelani-Akande TA, Okunola AA, Dada O. 2018. Effect of operational parameters, characterization and antibacterial studies of green synthesis of silver nanoparticles, using Tithonia diversifolia. PeerJ 6: 1-17. DOI: 10.7717 /peerj.5865.

Fatimah I, Aftrid ZHVI. 2019. Characteristics and antibacterial activity of green synthesized silver nanoparticles using red spinach (Amaranthus tricolor L.) leaf extract. Green Chem Lett Rev 12 (1): 25-30. DOI: 10.1080/17518253.2019.1569729.

Goswami P, Mathur J. 2019. Positive and negative effects of nanoparticles on plants and their applications in agriculture. Plant Sci Today 6 (2): 232-242. DOI: 10.14719/pst.2019.6.2.502.

Gottardo, Mech A, Drbohlavova J, Malyska A, Bøwadt S, Sintes JR, Rauscher H. 2021. Towards safe and sustainable innovation in nanotechnology: State-of-play for smart nanomaterials. NanoImpact 21: 1-10. DOI: 10.1016/j.impact.2021.100297.

Guo KW. 2012. Green nanotechnology of trends in future energy: A review. Intl J Energy Res 36 (1): 1-17. DOI: 10.1002/er.1928.

Hagerman AE, Riedl, KM, Jones GA, Sovik KN, Ritchard NT, Hartzfeld PW, Riechel TL. 1998. High molecular weight plant polyphenolics 
(tannins) as biological antioxidants. J Agric Food Chem 46 (5): 1887 1892. DOI: 10.1021/jf970975b.

Ider M, Abderrafi K, Eddahbi, Ouaskit S, Kassib A. 2017. Silver metallic nanoparticles with surface plasmon resonance: Synthesis and characterizations. J Clust Sci 28 (3): 1051-1069. DOI 10.1007/s10876-016-1080-1.

Insanu M, Kusmardiyani S, Hartati R. 2014. Recent studies on phytochemicals and pharmacological effects of Eleutherine americana Merr. Proc Chem 13: 221-228. DOI: 10.1016/j.proche.2014.12.032.

Iravani S, Varm RS. 2020. Green synthesis, biomedical and biotechnological applications of carbon and graphene quantum dots. A review. Environ Chem Lett 18 (3): 703-727. DOI: 10.1007/s10311020-00984-0.

Jalilian F, Chahardoli A, Sadrjavadi K, Fattahi A, Shokoohinia Y. 2020. Green synthesized silver nanoparticle from Allium ampeloprasum aqueous extract: Characterization, antioxidant activities, antibacterial and cytotoxicity effects. Adv Powder Technol 31 (3): 1323-1332. DOI: $10.1016 /$ j.apt.2020.01.011.

Kaabipour S, Hemmati S. 2021. A review on the green and sustainable synthesis of silver nanoparticles and one-dimensional silver nanostructures. Beilstein J Nanotechnol 12 (1): 102-136. DOI: 10.3762/bjnano.12.9.

Kamarudin AA, Sayuti NH, Saad N, Razak NAA, Esa NM. 2021. Eleutherine bulbosa (Mill.) Urb. bulb: Review of the pharmacologica activities and its prospects for application. Intl J Mol Sci 22 (13): 1-20. DOI: 10.3390/ijms22136747.

Kedi PBE, Meva FE, Kotsedi L, Nguemfo EL, Zangueu CB, Ntoumba AA, Mohamed HEA, Dongmo AB, Maaza M. 2018. Eco-friendly synthesis, characterization, in vitro and in vivo anti-inflammatory activity of silver nanoparticle-mediated Selaginella myosurus aqueous extract. Intl J Nanomed 13: 8537-8548. DOI: 10.2147/IJN.S174530.

Kumar P, Senthamil S, Lakshmi A, Kumar K, Ganeshkumar R, Govindaraju M. 2012. Synthesis of silver nanoparticles from Sargassum tenerrimum and screening phytochemicals for its antibacterial activity. Nano Biomed Eng 4 (1): 12-16. DOI: 10.5101/nbe.v4i1.p12-16

Kuntorini EM, Dewi M, Misrin M. 2016. Anatomical structure and antioxidant activity of red bulb plant. Biodiversitas 17 (1): 229-233. DOI: $10.13057 /$ biodiv/d170133.

Lateef A, Ojo SA, Akinwale AS, Azeez L, Gueguim-Kana EB, Beukes LS. 2015. Biogenic synthesis of silver nanoparticles using cell-free extract of Bacillus safensis LAU 13: Antimicrobial, free radical scavenging and larvicidal activities. Biologia 70 (10): 1295-1306. DOI: $10.1515 /$ biolog-2015-0164.

Mahabusarakam, W, Hemtasin C, Chakthong S, Voravuthikunchai SP, Olawumi IB. 2010. Naphthoquinones, anthraquinones and naphthalene derivatives from the bulbs of Eleutherine americana. Planta Medica 76 (4): 345-349. DOI: 10.1055/s-0029-1186143.

Mustafa RA, Abdul A, Mohamed S, Bakar FA. 2010. Total phenolic compounds, flavonoids, and radical scavenging activity of 21 selected tropical plants. J Food Sci 75 (1): 28-35. DOI: 10.1111/j.1750 3841.2009.01401.x.

Nahar KN, Rahaman M, Khan G, Islam M, Al-Reza, SM. 2021. Green synthesis of silver nanoparticles from Citrus sinensis peel extract and its antibacterial potential. Asian J Green Chem 5 (1): 135-150.

Nugroho RA, Hindryawati N, Aryani R, Manurung H, Sari YP, Nurti DD, Rudianto R, Prahastika W, Zahida F. 2021. Biosynthesis of silver nanoparticles from aqueous extract of Myrmecodia pendans bulb. AIP Conf Proc 2331: 1-7. DOI: 10.1063/5.0041654

Nuryanto MK, Paramita S. 2018. Anti-inflammatory activity of bawang Dayak (Eleutherine bulbosa (Mill. Urb.)) ethanol bulb extracts. J Vocational Health Stud 2: 51-55. DOI: 10.20473/jvhs.V2.I2.2018.5155.

Oda AM, Abdulkadhim H,Jabuk SI, Hashim R, Fadhil I, Alaa D, Kareem A. 2019. Green synthesis of silver nanoparticle by cauliflower extract: characterisation and antibacterial activity against storage. IET Nanobiotechnol 13 (5): 530-535. DOI: 10.1049/iet-nbt.2018.5095.

Pandian AMK, Karthikeyan C, Rajasimman M, Dinesh MG. 2015. Synthesis of silver nanoparticle and its application. Ecotoxicol Environ Saf 121: 211-217. DOI: 10.1016/j.ecoenv.2015.03.039.

Panneerselvam C, Ponarulselvam S, Murugan K. 2011. Potential antiplasmodial activity of synthesized silver nanoparticle using Andrographis paniculata Nees (Acanthaceae). Arch Appl Sci Res 3 (6): 208-217.

Phoem AN, Mayiding, Saedeh F, Permpoonpattana P. 2019. Evaluation of Lactobacillus plantarum encapsulated with Eleutherine americana oligosaccharide extract as food additive in yoghurt. Braz J Microbiol 50 (1): 237-246. DOI: $10.1007 / \mathrm{s} 42770-018-0017-2$.

Prathna T, Chandrasekaran N, Raichur AM, Mukherjee A. 2011. Biomimetic synthesis of silver nanoparticles by Citrus limon (lemon) aqueous extract and theoretical prediction of particle size. Colloids Surf B 82 (1): 152-159. DOI: 10.1016/j.colsurfb.2010.08.036.

Rai N, Shukla TP, Loksh KR, Karole S.2020. Synthesized silver nanoparticle loaded gel of Curcuma caesia for effective treatment of acne. J Drug Deliv Ther 10: 75-82. DOI: 10.22270/jddt.v10i6-s.4453.

Restrepo CV, Villa CC. 2021. Synthesis of silver nanoparticles, influence of capping agents, and dependence on size and shape: A review. Environ Nanotechnol Monit Manag 15: 1-11. DOI: 10.1016/j.enmm.2021.100428

Saragih B, Pasiakan M, Wahyudi D. 2014. Effect of herbal drink plants Tiwai (Eleutherine Americana Merr) on lipid profile of hypercholesterolemia patients. Intl Food Res J 21 (3): 1199-1203.

Senguttuvan J, Paulsamy S, Karthika K. 2014. Phytochemical analysis and evaluation of leaf and root parts of the medicinal herb, Hypochaeris radicata $\mathrm{L}$. for in vitro antioxidant activities. Asian Pac J Trop Biomed 4: 359-367. DOI: 10.12980/APJTB.4.2014C1030.

Singh R, Lillard JW Jr. 2009. Nanoparticle-based targeted drug delivery. Exp Mol Pathol 86 (3): 215-223. DOI: 10.1016/j.yexmp.2008.12.004.

Song SH, Min HY, Han AR, Nam JW, Seo EK, Park SW, Lee SH, Lee, SK. 2009. Suppression of inducible nitric oxide synthase by $(-)$ isoeleutherin from the bulbs of Eleutherine americana through the regulation of NF- $\mathrm{KB}$ activity. Intl Immunopharmacol 9 (3): 298-302. DOI: 10.1016/j.intimp.2008.12.003.

Umadevi M, Shalini S, Bindhu M. 2012. Synthesis of silver nanoparticle using D. carota extract. Adv Nat Sci Nanosci Nanotechnol 3 (2): 1-6. DOI: $10.1088 / 2043-6262 / 3 / 2 / 025008$.

Usman M, Farooq M, Wakeel A, Nawaz A, Cheema SA, ur Rehman, H., Ashraf I, Sanaullah M.2020. Nanotechnology in agriculture: Current status, challenges and future opportunities. Sci Total Environ 721: 116. DOI: $10.1016 /$ j.scitotenv.2020.137778.

Uzair B, Liaqat A, Iqbal H, Menaa B, Razzaq A, Thiripuranathar G, Fatima N, Menaa F. 2020. Green and cost-effective synthesis of metallic nanoparticles by algae: Safe methods for translational medicine. Bioengineering 7 (4): 1-22. DOI: 10.3390/bioengineering7040129.

Velsankar RMK, Preethi R, Muthulakshmi V, Sudhahar S. 2020. Green synthesis of $\mathrm{CuO}$ nanoparticles via Allium sativum extract and its characterizations on antimicrobial, antioxidant, antilarvicidal activities. J Environ Chem Eng 8 (5): 1-13. DOI: 10.1016/j.jece.2020.104123.

Vijayakumar S, Malaikozhundan B, Saravanakumar K, Durán-Lara EF, Wang MH, Vaseeharan B. 2019. Garlic clove extract assisted silver nanoparticle-Antibacterial, antibiofilm, antihelminthic, antiinflammatory, anticancer and ecotoxicity assessment. J Photochem Photobiol B Biol 198: 1-12. DOI: 10.1016/j.jphotobiol.2019.111558.

Zhang P, Guo Z, Ullah S, Melagraki G, Afantitis A, Lynch I. 2021. Nanotechnology and artificial intelligence to enable sustainable and precision agriculture. Nat Plant 7 (7): 864-876. DOI: 10.1038/s41477021-00946-6. 